\title{
Person-centered dementia care in acute hospital wards - the influence of staff knowledge and attitudes
}

\begin{abstract}
Person-centered dementia care practices in acute hospital wards are suboptimal and not commonly measured. Although previous research has indicated that the work environment of staff influences their perceptions of person-centeredness, few studies have examined how their personal attributes, such as their level of dementia knowledge and attitudes, influence their person-centered dementia care practices. A questionnaire was distributed to test the relationship between staff perceptions of person-centered dementia care and their dementia knowledge and attitudes in general medical wards. The results showed that staff with better dementia knowledge were significantly more critical about the extent they were using evidence-based guidelines and external expertise. Staff with better attitudes perceived themselves as using more individualized care practices. The findings demonstrate that to enhance person-centered dementia care in acute hospitals, staff training programs should develop both their intellectual and interpersonal skills to improve their knowledge and attitudes.
\end{abstract}




\section{Highlights:}

- Achieving person-centered dementia care in hospitals is challenging for staff partly due to their lack of educational preparation

- Only $40 \%$ of participants (hospital staff) had previous training in dementia

- The more the staff were knowledgeable about dementia, the more critical they were about the level of person-centered care they delivered

- The more positive were the attitudes of the staff towards persons with dementia, the more they perceived were individualizing their care

Keywords: dementia; person-centered care; acute hospitals; knowledge; attitudes; evidencebased guidelines 


\section{Introduction}

The Global Burden of Disease Study $2016^{1}$ estimated that there were 43.8 million people with dementia worldwide (equivalent to $0.59 \%$ of the world population) but the number of individuals has more than doubled since the year 1990. By 2030 and 2050, this figure is projected to increase to 82 million and 152 million respectively $(1.56 \%$ of the global population). ${ }^{2}$ It is estimated that currently there are approximately 7,000 persons with dementia in the Maltese Islands with this number expected to rise to 12,955 (equivalent to $3.26 \%$ of the total population) by the year $2050 .^{3}$ In 2012 , a report ${ }^{4}$ commissioned by the World Health Organization and Alzheimer Disease International identified dementia as a public health priority and encouraged countries to raise awareness with the hope of improving the treatment and care worldwide.

Apart from cognitive impairment, persons with dementia may experience additional comorbidities that put them at a higher risk of being admitted to an acute hospital. ${ }^{5}$ However, during their hospital stay these patients may also experience functional decline and increasing their length of stay, ${ }^{6}$ putting them at a higher risk of being discharged to a care home and leading to further financial costs for local health and social care services. ${ }^{7}$ Persons with dementia and family caregivers have reported negative experiences of hospital stay ${ }^{8,9}$ whilst staff felt that caring for these patients is very challenging. ${ }^{10}$ These studies indicate that staff working in acute hospitals require further knowledge, attitudes and skills through training in order to provide care that is tailored to the needs of these patients. ${ }^{11}$

Person-centered care has been advocated as the gold-standard model of care for older persons ${ }^{12}$ and persons with dementia. ${ }^{13}$ Although there is no single definition of the term 'person- 
centered care', a narrative review identified a number of common themes that seem to form the core of person-centered practices; patient participation and involvement, the relationship between the patient and the healthcare professional (regardless of professional group) and the importance of the context where care is delivered. ${ }^{14}$ Within the context of dementia care, Brooker $^{13}$ identified four core themes that is valuing people by promoting the rights of the person; individualizing the care to meet their needs; understanding the care from the perspectives of the persons with dementia and their family member and fostering social environments which enable person to remain in relationships. Moreover, person-centred care has been defined by persons with dementia, their family members and staff as approaches that promote a continuation of self and normality. ${ }^{15}$ However, this may be difficult to achieve in busy acute hospital wards unless staff are not trained and supported to do so.

There is a need to identify what factors influence person-centered practices in acute hospitals wards. A realist review of dementia-friendly interventions to change the care of persons with dementia admitted in hospitals, indicated that staff need to have the confidence to change work practices to individualize the care. ${ }^{16}$ Although confidence and care efficacy has been shown to improve through staff training, ${ }^{17}$ the direct link between dementia knowledge and personcentred care practices has not been clearly studied. Lin et al, ${ }^{18}$ found that whilst hospital nursing staff may have accurate dementia knowledge in terms of severity and symptomatology, they may still find difficulty in choosing person-centered care practices. Moreover, other studies have indicated that improving staff knowledge through training does not necessarily introduce and maintain person-centered care practices in acute hospitals. ${ }^{19}$

Few studies have sought to investigate how personal attributes of hospital staff, in particular their level of dementia knowledge and attitudes, influence the person-centered dementia care 
practices adopted in this setting. As a result, the aim of the present study was to test the relationship between the level of person-centered dementia care practices as rated by staff working in acute hospital wards with their knowledge and attitudes towards persons with dementia. It was hypothesized that staff with better dementia knowledge and attitudes would perceive to be working at a higher level of person-centeredness in the acute hospital wards. The objectives of the study were to:

- measure the level of person-centeredness of hospital staff working in acute medical wards

- measure the hospital staff knowledge and attitudes towards persons with dementia

- relate the staff knowledge and attitudes with their perceived level of person-centeredness towards persons with dementia in their wards.

\section{Methods}

\section{Participants}

The study was conducted in a hospital in Malta. The population consisted of all full-time staff working in eleven acute medical wards and medical assessment units (MAU). The decision to restrict selection from medical wards was taken to enable data collection with a relatively homogenous group with similar ward cultures A total of 198 staff members were invited to participate consisting of all full-time staff working in these wards including charge nurses, staff nurses, nursing aids/care workers, doctors and physiotherapists. and occupational therapists. All the interdisciplinary team members were considered as participants since patients with dementia in acute hospitals will most likely require the assessment and management of different team members ${ }^{20}$ and a team-based approach has been recommended as the best model of care for persons with dementia ${ }^{21}$. Whilst the academic preparation and clinical training of these staff may vary, all acute care staff, including care workers, should have been in contact with persons with dementia and the contribution of all members of team have a direct influence 
on the patient's and family member's hospital experience. Consequently, all staff members were considered as suitable participants for this study.

The questionnaires were distributed by hand to all charge nurses of the eleven medical wards who acted as intermediaries and were asked to distribute to all full-time staff who were working in their ward at the time of the data collection. Once they completed the questionnaire, they were asked to leave them in an envelope that was left with the charge nurse of each ward. Data collection was conducted during the months of May-June 2018. One hundred and thirty-two staff members (response rate $=67 \%$ [margin of error: $\pm 4.94 \%$ ]) participated by filling in the questionnaire.

\section{Data collection}

A self-administered questionnaire was distributed and consisted of three validated tools used to measure dementia knowledge (Alzheimer Disease Knowledge Scale (ADKS)), attitudes (Dementia Attitude Scale (DAS)) and the extent to which staff perceived they were providing person-centered dementia care (Person-centered care of older people with cognitive impairment in acute care scale (POPAC)), together with demographic variables. These included gender, nationality, age, current occupation, maximum level of education attained, whether they had any previous training on dementia or cognitive impairment, who organized the training and the number of hours of training attended, whether they have worked in a geriatric or psychiatric setting, whether they have/had family members with cognitive impairment and whether they usually took care of persons with dementia or cognitive impairment at their place of work. Another question sought to rate their experience when caring for patients with cognitive impairment at work using a Likert scale from very positive (1) to very negative (5). Permissions were obtained from all authors who developed the tools. 
The $\mathrm{ADKS}^{22}$ contains 30 true/false items to assess knowledge about Alzheimer Disease. A total score, ranging from $0-30$, is obtained by adding the correct scores for each statement. The scale was designed for use with students, healthcare professionals, and the general public and takes a maximum of 10 min to complete. The questions focus on seven subscales that characterize knowledge about $\mathrm{AD}$ namely on: risk factors, assessment and diagnosis, symptoms, disease progression, life impact, caregiving, treatment and management. An analysis of the scale's psychometric properties suggests it has adequate reliability and content, predictive, concurrent, and convergent validity. ${ }^{22}$

The Dementia Attitude Scale (DAS) is a 7-point Likert scale of 20 items that reflect the affective, Behavioural and cognitive components of the attitudes towards individuals with dementia. ${ }^{23}$ The DAS has two factor components namely 'dementia knowledge' and 'social comfort' and has adequate reliability and convergent validity when compared to similar scales. The higher the DAS score the more positive is the participants' attitudes towards persons with dementia.

The POPAC scale ${ }^{24}$ aims to measure staff perceptions of person-centered care and responses are given on a 6-point Likert-type scale ranging from (1) 'never,' to (6) 'always'. The scale consists of three subscales; 'using cognitive assessments and care interventions', 'using evidence and cognitive expertise' and 'individualizing care'. Scale scores and total scores can range between 15 and 90 with higher scores indicating a higher degree of person-centeredness. Both the Swedish ${ }^{21}$ and the English version ${ }^{14}$ have been found to have good psychometric properties. 


\section{Ethical considerations}

Ethical approval was sought and granted from the University Research Ethics Committee of the University of Malta. Permission was also given from the administration of the participating hospital. A cover letter was included with the questionnaire and distributed to the staff explaining the aims and objectives of the study. One hard copy of the questionnaire was distributed to the selected wards. To maintain anonymity, staff were asked to leave the completed questionnaires in a box-file at the nursing station. Staff were informed that participation was voluntary and confidentiality would be maintained. ${ }^{25}$

\section{Data analysis}

The data obtained was analyzed using Predictive Analysis Software (PASW) Statistics (Version 24). Test of normality conducted using the Shapiro-Wilk Test. Whilst DAS and POPAC scores and their sub-domains were normally distributed, ADKS scores were not. Therefore, the Spearman's rho coefficient test was used to compare means when ADKS scores were used whilst the Pearson's coefficient was utilized for DAS and POPAC scores. For continuous by categorical relationships (mean ADKS/DAS/POPAC scores and their subdomains vs. age groups, gender, occupation, nationality) Analysis of variance (ANOVA, for parametric data) and the Kruskal-Wallis (for non-parametric data) tests were used.

A stepwise regression was also carried out to identify the most significant predictors of the perceived level of person-centeredness in the hospital wards, taking the demographic variables, knowledge and attitudes of the staff as dependent variables. Each of these variables were added until the model with the highest adjusted $\mathrm{R}$ square was found. 
In this study, the internal consistency for the three scales was found to be good for the POPAC scale (Cronbach's $\alpha=0.82)$ and for the DAS scale (Cronbach's $\alpha=0.78)$ and acceptable for the ADKS scale (Cronbach's $\alpha=0.64)$.

\section{Results}

Demographic characteristics of participants

Table 1 describes the demographic characteristics of the respondents, the majority were Maltese $(n=108 ; 82 \%)$, female $(n=97 ; 73 \%)$, nurses $(n=92 ; 70 \%)$ in their 30 s $($ mean $=31 \pm 10.3)$. Approximately two-thirds of the respondents $(n=101 ; 68 \%)$ had at least a diploma or a degree qualification (equivalent to European Qualification Framework ${ }^{26}$ levels 6 and 7). Only 39\% $(n=51)$ of the respondents had previous training in dementia care with the latter being organized either by the hospital or the University of Malta. Almost all participants $(n=116 ; 90 \%)$ responded that they have cared for persons with dementia at work with the majority of staff reporting having negative experiences. Whilst 40 participants (34\%) rated their experience working with patients with dementia as positive or very positive, there were 18 hospital staff $(16 \%)$ who rated their experience as negative or very negative, with $74(58 \%)$ of the staff rating it as neutral. Their perceived experience of working with persons with dementia was significantly associated with their attitudes towards these patients $(F=3.72 ; p=0.007)$.

\section{(Insert Table 1)}

\section{Hospital staff perceived level of person-centeredness}

With a total mean of $57.88 \pm 10.28$, the majority of the participants tended to perceive themselves practicing in a person-centered way. The subscale 'Using evidence and expertise in cognition' of the POPAC scale scored the highest mean score (mean $=4.16 \pm 0.96)$ followed 
by 'Individualizing care' (mean $=3.88 \pm 0.85$ ) and 'Using cognitive assessments/ care interventions' (mean=3.65 \pm 0.77 ). Table 2 summarizes the mean and standard deviation of each item of the POPAC scale. The item which scored the highest was 'We involve family members in the care of older patients with cognitive impairment' (Mean $=4.79 \pm 0.95)$ whilst the lowest was the item 'We leave older people with cognitive impairments alone in the ward' $($ mean=1.98 \pm 1.23$)$.

(Insert Table 2)

Hospital staff knowledge and attitudes towards persons with dementia

Table 3 relates to staff knowledge, attitudes and perceptions of using PCC practices. The mean ADKS score was $20.37 \pm 3.72$ ( $\mathrm{n}=$ equivalent to $68 \%$ of correct answers. Staff, in general, had a positive attitude towards patients with dementia (mean DAS=99.45 \pm 12.52 ). Knowledge scores were significantly related with whether hospital staff were Maltese nationals or not (F value $=7.904 ; \mathrm{p}=0.006)$ and whether they had a family member with dementia $(\mathrm{F}$ value $=6.995$; $\mathrm{p}=0.009)$. Attitudes scores differed between gender $(\mathrm{F}$ value $=6.511 ; \mathrm{p}=0.012)$; according to age (Pearson coefficient $=-0.283 ; \mathrm{p}=0.002$ ) and their perceived experience of working with dementia patients $(\mathrm{F}$ value $=3,715 ; \mathrm{p}=0.007)$.

\section{(Insert Table 3)}

Relationship between dementia knowledge/attitudes and level of person-centeredness as perceived by hospital staff in their wards

Whilst the mean attitude scores (DAS) were positively related with the POPAC scores (Pearson's coefficient $=0.311 ; \mathrm{p}=0.001$ ), ADKS scores were found to be negatively related (Spearman=-0.205; $\mathrm{p}=0.026$ ). This could indicate that staff with better dementia knowledge 
were more negative about the level of person-centered care they were providing. However, when comparing the POPAC sub-scales scores with the knowledge scores, the sub-scale 'using evidence based guidelines and expertise' was the only scale to be negatively associated with the knowledge score (Spearman=-0.204; $\mathrm{p}=0.027$ ). On the contrary, the mean score of the subscale related to 'practices that individualize the care' was the most positively related to the mean staff attitudes scores (Spearman=0.336; $\mathrm{p}<0.001$ ). The mean POPAC scores were found to be negatively related with staff age (Pearson correlation $=-0.270 ; p=0.003$ ) and varied across occupations $(\mathrm{F}=2.821 ; \mathrm{p}=0.007)$, with medical doctors and charge nurses obtaining the lowest scores (Table 4).

(Insert Table 4)

A stepwise regression analysis was performed to predict the POPAC scores with knowledge, attitude scores and binary/ordinal demographic variables (gender, nationality, age, educational level, previous training, previous work, being a family member) acting as possible predictors (Table 5). A significant regression value was found $(\mathrm{F}=7.33 ; \mathrm{p}<0.001)$ that was based on a three-predictor model that retained dementia knowledge, attitudes and the participants' age, which together explained $17 \%$ of the variance in the retained model.

\section{(Insert Table 5)}

\section{Discussion}

\section{Demographic characteristics of participants}

The study investigated the relationship between the level of person-centered dementia care practices as rated by staff working in acute hospital wards with their knowledge and attitudes towards persons with dementia. The results indicated that although almost all hospital staff 
were caring for patients with dementia and cognitive impairment at work, only $40 \%$ of the participants reported to have attended some form of dementia care training. Similarly, around $54 \%$ of health care staff working (doctors, nurses and healthcare assistants) in $\mathrm{UK}^{11}$ and $87 \%$ of nurses in Ireland ${ }^{27}$ who work in acute hospital settings did not perceive their training in dementia care to be 'sufficient'.

\section{Staff knowledge and its relationship to person-centeredness in hospital wards}

Knowledge about dementia of the participants in this study was unsurprisingly higher than for nursing students in Malta $^{28}$ (64\% correct answers), similar to Maltese nurses working in longterm care $^{29}$ ( $68 \%$ correct answers), but significantly lower than health care staff in an Australian hospital $^{30}$ (79\% correct answers). Similar to the latter study ${ }^{30}$, staff who cared for family members with dementia had significantly higher mean knowledge scores. This could be attributed to the fact that staff who have family members with dementia are more motivated to learn about the condition. Alternatively, the difference in dementia knowledge of hospital staff across countries could be due to their varied educational preparation making comparison relatively difficult. For example, Hallberg et $\mathrm{al}^{31}$ found that educational background of professional care providers in dementia care varied considerably across eight European countries.

The results also showed that hospital staff with better dementia knowledge were significantly more critical about the level of person-centeredness they deliver especially on the way they were using evidence-based guidelines, cognitive assessment tools and refer to other clinical experts in dementia care. Moreover, older staff were more critical of the level of personcenteredness they provide. This difference could have been moderated by staff occupation, since staff in different age cohorts occupied different occupations. For example, charge nurses 
were older than registered nurses (mean age: charge nurses: 43 years; registered nurses: 28 years). The study indicated that hospital staff who are were older and in different occupational levels have a negative perception of the level of person-centered-care they deliver. Similarly, Grealish et $\mathrm{al}^{32}$ found that enrolled nurses (a second level nurse who provides direct care under the supervision of a registered nurse) scored significantly higher in their perception of personcenteredness than registered nurses. According to these authors, this difference was attributed to the fact that enrolled nurses were more actively involved in person-centered care practices as they worked closely with patients. However, the negative relation between dementia knowledge and perceived level of person-centeredness found in the current study lends to an alternative hypothesis - that professions with better dementia knowledge may be more aware of the available evidence-based dementia guidelines and tools and are able to identify the difference between 'what should be' and 'what is actually being practiced'. Increasing awareness of these evidence based guidelines and tools through staff development resulted in significantly higher levels of person-centeredness in residential care. ${ }^{33}$ Further studies need to be carried out on how these guidelines can be implemented in acute hospitals. However, this study indicated that increased staff awareness of clinical guidelines through better dementia knowledge could contribute towards acknowledging the need for their implementation in practice. This is in line with a systematic meta-review which found that health care professionals' awareness about the existence of clinical guidelines and their familiarity with their content affects their implementation. ${ }^{34}$

Besides dementia knowledge and attitudes of staff, other psychological and contextual factors can play an important role in implementing person-centered care guidelines in general hospitals. Numerous studies have related person-centred care as perceived by care staff to the context of care or work environment such as job satisfaction of the staff, ${ }^{35}$ perceived levels of job strain, stress of conscience and psychological support. ${ }^{36}$ Although these domains have not 
been investigated in the present study, it could be that older participants with better dementia knowledge were experiencing burnout or compassion fatigue in view of the longer time caring for patients with dementia (being significantly older), the higher level of responsibility (being most likely charge nurses/doctors) and the sense of frustration of not being able to change practice. Similarly, Shinan-Altman et $\mathrm{al}^{37}$ found that role conflict and role ambiguity of social workers and nurses working in nursing homes and hospitals, were significantly associated with burnout. Considering that the number of nurses per population in Malta is below the European average ${ }^{38}$ the low staffing levels in the medical wards selected for this study could have also influenced the implementation of person-centered care practices and guidelines.

Referring patients who have been screened and identified with cognitive symptoms, for specialized follow-up services, is an important component of quality of care. ${ }^{39}$ This study indicated that the extent staff consult with specialist expertise, if the patient is suspected to have cognitive impairment, was also related to their dementia knowledge (staff with more knowledge were less likely to refer patients for further follow-ups). Whilst there is evidence showing that referral to specialist services in primary health care is directly associated to the gaps in knowledge of primary care providers, ${ }^{40}$ there are no studies that relate the knowledge of hospital staff with their intention to refer patients with suspected cognitive impairment to specialist services. Consequently, further studies are needed on this important area of clinical practice.

\section{Staff attitudes and its relationship to person-centeredness in hospital wards}

Similar to other studies, ${ }^{41,42}$ the attitude of hospital staff towards persons with dementia was in general positive; although there was a significant variation according to gender (female staff reported more positive attitudes), age (the younger the age the better the attitudes) and how they rated their personal experience of working with these persons (staff perceiving more 
positive experience having better attitudes). However, whilst these studies ${ }^{41,42}$ found that the attitude of hospital staff was associated with their occupation, this was not found in our study, possibly due to the smaller sample size. Moreover, the relationship between decreasing attitude score and increasing age, has also been found in some studies ${ }^{42,43}$ but not in others ${ }^{41}$. Staff attitude scores were significantly related with their experience of working with persons with dementia. This is congruent with other studies carried out in residential homes, ${ }^{44,45}$ which found that staff attitudes were positively related with the level of job satisfaction experienced when working with residents with dementia. This shows that there is a need for staff to be provided with positive care experiences which can in turn improve their attitudes.

Staff with more positive attitudes towards patients with dementia perceived themselves as using more individualized care practices such as taking biographical information, involving the patients and family members in the care and discussing and evaluating whether the care is meeting their needs. However, better staff knowledge was not related with better perceived use of individualized practices. Similarly, Mullan and Sullivan ${ }^{46}$ found that whilst a positive attitude towards persons with dementia predicted a greater sense of competence in aged care staff, it was not related to staff knowledge and training.

Based on the findings of this study, staff development and dementia care training in acute hospitals should incorporate interpersonal and moral competencies to improve staff attitudes as well technical as well as intellectual competencies to increase awareness about evidence based guidelines for the assessment and management of persons with cognitive impairment and dementia. Similarly, dementia care competency frameworks for nurses ${ }^{47,48}$ recommend the importance of developing curricula and training programs with a set of competences that range from the attainment of technical/intellectual and interpersonal and attitudinal skills. This seems to be also important in acute hospitals in order to empower staff to implement person-centered 
care practices.

New models of organizing care for persons with dementia in general hospitals are being considered such as the setting of specialized dementia units, ${ }^{49,50}$ that are showing promising outcomes by improving patient's wellbeing and staff/relative satisfaction. Similar initiatives are being developed in other acute hospitals wards such as orthopedic wards ${ }^{51}$. An alternative approach is the recruitment of skilled dementia specialist nurses with the latter being described to benefit people with dementia in hospitals and their family carers. ${ }^{52}$ However, such initiatives require institutional and inter-personal investment and support and their benefits may be limited to a few individuals who are admitted to these units. Considering that the prevalence of dementia in acute hospitals is all the time increasing, a multi-level approach may be required that encompasses system and policy changes such as increasing staffing levels, providing continuous staff development and support and restructuring the hospital environment to become more dementia-friendly.

\section{Strengths and limitations of the study}

The study has a number of strengths and limitations. The study is one of the first that sought to relate hospital staff knowledge and attitudes with the level person-centered dementia care as perceived by the staff. Moreover, power analysis revealed that a response rate of $67 \%$ was adequate and a good representation of the targeted population under study.

However, the sample consisted of a homogeneous convenience in one acute hospital. This limits the generalizability of the findings. Moreover, due to social-desirability bias, perceptions of person-centered care practices as reported by staff may not correspond to the observed practices. This could have been a possible reason of why a high mean POPAC score was obtained in this study. Nevertheless, the aim of the study was not only to measure the level of 
person-centered care in acute hospitals as perceived by the staff but to determine how this domain is related to staff knowledge and attitudes. Comparing the knowledge and attitudes of different health care professionals and care workers in acute settings may be difficult since they could have had different academic and experiential preparation. Nevertheless, having an overview of dementia knowledge/attitudes across the team could shed light on the discrepancies in the academic preparation of these staff and help in targeting those staff members who require better educational development. Finally, the findings of this study may indicate that when measuring perceptions of person-centered dementia care, self -reported knowledge and attitudes towards dementia needs to be measured since these can influence the way staff perceived the level of person-centeredness in this setting.

\section{Conclusion}

The results of this study demonstrate that hospital staff need further training and support to improve their knowledge about and attitudes towards persons with dementia to enable them to provide quality dementia care and person-centered care practices. Dementia knowledge is essential for staff to become aware about the need of using evidence-based dementia care guidelines and a positive attitude about dementia facilitates the introduction of interpersonal person-centered care practices. Thus, training programs for acute care staff should seek to improve the knowledge base as well as changing attitudes. This can be encouraged by hospital administrators by training staff to develop both technical/intellectual skills as well as interpersonal/moral skills in dementia care.

\section{Acknowledgements}

A special thanks to the hospital staff who participated in the survey

\section{Conflict of interest}

None 


\section{Funding}

Funding was obtained from the University of Malta Research Seed Fund for 2018

(NURRP04-18)

\section{References:}

1. Nichols E, Szoeke CE, Vollset SE, Abbasi N, Abd-Allah F, Abdela J, Aichour MT, Akinyemi RO, Alahdab F, Asgedom SW, Awasthi A. Global, regional, and national burden of Alzheimer's disease and other dementias, 1990-2016: a systematic analysis for the Global Burden of Disease Study 2016. The Lancet Neurology. 2019 Jan 1;18(1):88-106.

2. World Health Organization. Global action plan on the public health response to dementia 2017-2025.

3. Scerri A, Scerri C. Dementia in Malta: new prevalence estimates and projected trends. Malta Medical Journal, 2012;24(3):21-24.

4. Wortmann M. Dementia: a global health priority-highlights from an ADI and World Health Organization report. Alzheimer's research \& therapy. 2012 Oct;4(5):40.

5. Mukadam N, Sampson EL. A systematic review of the prevalence, associations and outcomes of dementia in older general hospital inpatients. International Psychogeriatrics. 2011 Apr;23(3):344-55.

6. Connolly S, O'Shea E. The impact of dementia on length of stay in acute hospitals in Ireland. Dementia. 2015 Sep;14(5):650-8.

7. Alzheimer's Society. Counting the cost: Caring for people with dementia on hospital wards. Alzheimer's Society; 2009.

8. Digby R, Lee S, Williams A. The experience of people with dementia and nurses in hospital: an integrative review. Journal of clinical nursing. 2017 May;26(9-10):1152-71.

9. Scerri A, Scerri C, Innes A. The perceived and observed needs of patients with dementia admitted to acute medical wards. Dementia. 2018 Nov 27:1471301218814383.

10. Clissett P, Porock D, Harwood RH, Gladman JR. The challenges of achieving personcentered care in acute hospitals: a qualitative study of people with dementia and their families. International Journal of Nursing Studies. 2013 Nov 1;50(11):1495-503.

11. Gandesha A, Souza R, Chaplin R, Hood C. Adequacy of training in dementia care for acute hospital staff. Nursing Older People. 2012 Apr 27;24(4).

12. McCormack B. Person-centeredness in gerontological nursing: an overview of the literature. Journal of Clinical Nursing. 2004 Mar; 13:31-8.

13. Brooker D, Latham I. Person-centered dementia care: Making services better with the VIPS framework. Jessica Kingsley Publishers; 2015 Nov 21.

14. Kitson A, Marshall A, Bassett K, Zeitz K. What are the core elements of patient-centred care? A narrative review and synthesis of the literature from health policy, medicine and nursing. Journal of Advanced Nursing. 2013 Jan;69(1):4-15.

15. Edvardsson D, Fetherstonhaugh D, Nay R. Promoting a continuation of self and normality: person-centred care as described by people with dementia, their family members and aged care staff. Journal of Clinical Nursing. 2010 Sep;19(17-18):2611-8.

16. Handley M, Bunn F, Goodman C. Dementia-friendly interventions to improve the care of people living with dementia admitted to hospitals: a realist review. BMJ open. $2017 \mathrm{Jul}$ $1 ; 7(7): \mathrm{e} 015257$.

17. Surr CA, Smith SJ, Crossland J, Robins J. Impact of a person-centred dementia care training programme on hospital staff attitudes, role efficacy and perceptions of caring for 
people with dementia: A repeated measures study. International Journal of Nursing Studies. 2016 Jan 1;53:144-51.

18. Lin PC, Hsieh MH, Lin LC. Hospital nurse knowledge of and approach to dementia care. Journal of Nursing Research. 2012 Sep 1;20(3):197-207.

19. Yous ML, Ploeg J, Kaasalainen S, Martin LS. Healthcare professionals' perceptions of PIECES education in supporting care delivery for older adults with responsive behaviours of dementia in acute care. Gerontology \& Geriatrics Education. 2019 Feb 3:1-20.

20. Grand JH, Caspar S, MacDonald SW. Clinical features and multidisciplinary approaches to dementia care. Journal of Multidisciplinary Healthcare. 2011; 4:125.

21. Warshaw GA, Bragg EJ. Preparing the health care workforce to care for adults with Alzheimer's disease and related dementias. Health Affairs. 2014 Apr 1;33(4):633-41.

22. Carpenter BD, Balsis S, Otilingam PG, Hanson PK, Gatz M. The Alzheimer's Disease Knowledge Scale: development and psychometric properties. The Gerontologist. 2009 Mar 25;49(2):236-47.

23. O'Connor ML, McFadden SH. Development and psychometric validation of the Dementia Attitudes Scale. International Journal of Alzheimer's Disease. 2010;2010.

24. Nilsson A, Lindkvist M, Rasmussen BH, Edvardsson D. Measuring levels of personcenteredness in acute care of older people with cognitive impairment: evaluation of the POPAC scale. BMC Health Services Research. 2013 Dec;13(1):327.

25. Polit DF, Beck CT. Nursing research: Principles and methods. Lippincott Williams \& Wilkins; 2004.

26. Komissio E. Descriptors defining levels in the European Qualifications Framework (EQF).

27. Coffey A, Tyrrell M, Buckley M, Manning E, Browne V, Barrett A, Timmons S. A multicenter survey of acute hospital nursing staff training in dementia care. Journal of Clinical Nursing. 2014;2(4):39.

28. Scerri A, Scerri C. Nursing students' knowledge and attitudes towards dementia-A questionnaire survey. Nurse Education Today. 2013 Sep 1;33(9):962-8.

29. Scerri A, Scerri C. Outcomes in knowledge, attitudes and confidence of nursing staff working in nursing and residential care homes following a dementia training programme. Aging \& mental health. 2019 Aug 3;23(8):919-28.

30. Smyth W, Fielding E, Beattie E, Gardner A, Moyle W, Franklin S, Hines S, MacAndrew M. A survey-based study of knowledge of Alzheimer's disease among health care staff. BMC Geriatrics. 2013 Dec;13(1):2.

31. Hallberg IR, Cabrera E, Jolley D, Raamat K, Renom-Guiteras A, Verbeek H, Soto M, Stolt M, Karlsson S. Professional care providers in dementia care in eight European countries; their training and involvement in early dementia stage and in home care. Dementia. 2016 Sep;15(5):931-57.

32. Grealish L, Simpson T, Soltau D, Edvardsson D. Assessing and providing person-centered care of older people with cognitive impairment in acute settings: threats, variability, and challenges. Collegian. 2019 Feb 1;26(1):75-9.

33. Edvardsson D, Sandman PO, Borell L. Implementing national guidelines for personcentered care of people with dementia in residential aged care: effects on perceived personcenteredness, staff strain, and stress of conscience. International Psychogeriatrics. 2014 Jul;26(7):1171-9.

34. Francke AL, Smit MC, de Veer AJ, Mistiaen P. Factors influencing the implementation of clinical guidelines for health care professionals: a systematic meta-review. BMC medical informatics and decision making. 2008 Dec;8(1):38.

35. Edvardsson D, Fetherstonhaugh D, McAuliffe L, Nay R, Chenco C. Job satisfaction amongst aged care staff: exploring the influence of person-centered care provision. International Psychogeriatrics. 2011 Oct;23(8):1205-12. 
36. Sjögren K, Lindkvist M, Sandman PO, Zingmark K, Edvardsson D. To what extent is the work environment of staff related to person-centered care? A cross-sectional study of residential aged care. Journal of Clinical Nursing. 2015 May;24(9-10):1310-9.

37. Shinan-Altman S, Werner P, Cohen M. The connection between illness representations of Alzheimer's disease and burnout among social workers and nurses in nursing homes and hospitals: a mixed-methods investigation. Aging \& Mental Health. 2016 Apr 2;20(4):35261.

38. Azzopardi NM, Calleja N, Calleja A, Cylus J. Malta: Health system review. Health systems in transition. 2014;16(1):1-97.

39. Fix Dementia Care. Hospitals. Alzheimer's Society January. 2016 Jan.

40. Aminzadeh F, Molnar FJ, Dalziel WB, Ayotte D. A review of barriers and enablers to diagnosis and management of persons with dementia in primary care. Canadian Geriatrics Journal. 2012 Sep;15(3):85.

41. Nilsson A, Lindkvist M, Rasmussen BH, Edvardsson D. Staff attitudes towards older patients with cognitive impairment: need for improvements in acute care. Journal of Nursing Management. 2012 Jul;20(5):640-7.

42. de Vries K, Drury-Ruddlesden J, McGill G. Investigation into attitudes towards older people with dementia in acute hospital using the Approaches to Dementia Questionnaire. Dementia. 2019 Jun 21:1471301219857577.

43. Kada S, Nygaard HA, Mukesh BN, Geitung JT. Staff attitudes towards institutionalized dementia residents. Journal of clinical nursing. 2009 Aug;18(16):2383-92.

44. Moyle W, Murfield JE, Griffiths SG, Venturato L. Care staff attitudes and experiences of working with older people with dementia. Australasian Journal on Ageing. 2011 Dec;30(4):186-90.

45. Zimmerman S, Williams CS, Reed PS, Boustani M, Preisser JS, Heck E, Sloane PD. Attitudes, stress, and satisfaction of staff who care for residents with dementia. The Gerontologist. 2005 Oct 1;45(suppl_1):96-105.

46. Mullan MA, Sullivan KA. Positive attitudes and person-centered care predict of sense of competence in dementia care staff. Aging \& mental health. 2016 Apr 2;20(4):407-14.

47. Williams CL, Hyer K, Kelly A, Leger-Krall S, Tappen RM. Development of nurse competencies to improve dementia care. Geriatric Nursing. 2005 Mar 1;26(2):98-105.

48. Yamaguchi Y, Greiner C, Ryuno H, Fukuda A. Dementia nursing competency in acute care settings: A concept analysis. International journal of nursing practice. 2019 Apr:e12732.

49. Goldberg SE, Bradshaw LE, Kearney FC, Russell C, Whittamore KH, Foster PE, Mamza J, Gladman JR, Jones RG, Lewis SA, Porock D. Care in specialist medical and mental health unit compared with standard care for older people with cognitive impairment admitted to general hospital: randomised controlled trial (NIHR TEAM trial). BMJ. 2013 Jul 2;347:f4132.

50. Spencer K, Foster P, Whittamore KH, Goldberg SE, Harwood RH. Delivering dementia care differently - evaluating the differences and similarities between a specialist medical and mental health unit and standard acute care wards: a qualitative study of family carers' perceptions of quality of care. BMJ open. 2013 Dec 1;3(12):e004198.

51. Gill N, Hammond S, Cross J, Smith T, Lambert N, Fox C. Optimising care for patients with cognitive impairment and dementia following hip fracture. Zeitschrift für Gerontologie und Geriatrie. 2017 May 1;50(2):39-43.

52. Griffiths P, Bridges J, Sheldon H, Thompson R. The role of the dementia specialist nurse in acute care: a scoping review. Journal of Clinical Nursing. 2015 May;24(9-10):1394-405. 
Table 1. Demographic characteristics of hospital staff participating in the study $(\mathbf{N}=132)$

\begin{tabular}{|c|c|}
\hline $\begin{array}{l}\text { Gender } \\
\text { Male } \\
\text { Female }\end{array}$ & $\begin{array}{l}35(27 \%) \\
97(73 \%)\end{array}$ \\
\hline $\begin{array}{l}\text { Nationality } \\
\text { Maltese } \\
\text { Other } \\
\text { Missing Data }\end{array}$ & $\begin{array}{l}108(82 \%) \\
20(15 \%) \\
4(3 \%)\end{array}$ \\
\hline Mean age (years \pm SD) [median] & $31 \pm 10.3[27]$ \\
\hline $\begin{array}{l}\text { Occupation } \\
\text { Care worker } \\
\text { Nursing Officer/Deputy Nursing Officer } \\
\text { Medical Doctor } \\
\text { Nurse } \\
\text { Therapists (Occupational Therapists, Physiotherapists) } \\
\text { Social Worker } \\
\text { Others }\end{array}$ & $\begin{array}{l}11(8 \%) \\
9(7 \%) \\
5(4 \%) \\
92(70 \%) \\
7(5 \%) \\
1(1 \%) \\
7(5 \%) \\
\end{array}$ \\
\hline $\begin{array}{l}\text { Maximum level of education according to the European } \\
\text { Qualification Framework }{ }^{\&} \\
\text { Level } 2 \\
\text { Level } 3 \\
\text { Level } 4 \\
\text { Level } 5 \\
\text { Level } 6 \\
\text { Level } 7 \\
\text { Missing }\end{array}$ & $\begin{array}{l}13(10 \%) \\
8(6 \%) \\
9(7 \%) \\
33(25 \%) \\
27(20 \%) \\
41(31 \%) \\
1(1 \%)\end{array}$ \\
\hline $\begin{array}{l}\text { Attended previous training on dementia } \\
\text { Yes } \\
\text { No } \\
\text { Missing }\end{array}$ & $\begin{array}{l}51(39 \%) \\
79(60 \%) \\
2(1 \%)\end{array}$ \\
\hline $\begin{array}{l}\text { Who organized the training }(N=51) ? \\
\text { Hospital } \\
\text { University } \\
\text { Others }\end{array}$ & $\begin{array}{l}18(35 \%) \\
18(35 \%) \\
15(30 \%) \\
\end{array}$ \\
\hline Mean hours of previous training $(\mathrm{N}=41)$ (hours $\pm \mathrm{SD})$ [median] & $16.0 \pm 0.42[8]$ \\
\hline $\begin{array}{l}\text { Previous experience in geriatric/psychiatric settings } \\
\text { Yes } \\
\text { No } \\
\text { Missing }\end{array}$ & $\begin{array}{l}101(77 \%) \\
29(22 \%) \\
2(1 \%)\end{array}$ \\
\hline $\begin{array}{l}\text { Family member with dementia } \\
\text { Yes } \\
\text { No } \\
\text { Missing }\end{array}$ & $\begin{array}{l}34(25 \%) \\
87(66 \%) \\
11(8.3 \%) \\
\end{array}$ \\
\hline $\begin{array}{l}\text { Cared for persons with dementia at work } \\
\text { Yes } \\
\text { No } \\
\text { Missing }\end{array}$ & $\begin{array}{l}116(88 \%) \\
14(11 \%) \\
2(1 \%) \\
\end{array}$ \\
\hline $\begin{array}{l}\text { Perceived experience of working with dementia patients as } \\
\text { graded by staff* (grade } \pm \text { SD) [median] }\end{array}$ & $2.7 \pm 0.67(3)$ \\
\hline
\end{tabular}

*Perceived experience: Range from very positive (1) to very negative (5)

${ }^{\&}$ European Qualification Framework Levels 
Table 2. Mean and standard deviation of each item of the POPAC scale

\begin{tabular}{|c|c|c|}
\hline Statements & $\begin{array}{l}\text { Mean } \\
\text { Score }\end{array}$ & $\begin{array}{l}\text { Standard } \\
\text { Deviation }\end{array}$ \\
\hline 1. We assess the cognitive status of our older patients on admission & 4.63 & 1.31 \\
\hline $\begin{array}{l}\text { 2. We make environmental adjustments to avoid over-stimulation in older people with } \\
\text { cognitive impairment (e.g. single rooms, noise reductions etc.) }\end{array}$ & 3.66 & 1.54 \\
\hline 3. We diagnose symptoms of cognitive impairment (e.g. dementias, delirium etc.) & 4.01 & 1.38 \\
\hline $\begin{array}{l}\text { 4. We spend more time with older patients with cognitive impairments as compared to } \\
\text { cognitively intact patients }\end{array}$ & 3.97 & 1.15 \\
\hline 5. We leave older people with cognitive impairments alone in the ward & 1.98 & 1.23 \\
\hline $\begin{array}{l}\text { 6. We use evidence-based tools to assess cognitive status of older patients (e.g. the } \\
\text { MMSE, SPMSQ, CAM etc.) }\end{array}$ & 3.62 & 1.43 \\
\hline $\begin{array}{l}\text { 7. We consult specialist expertise (e.g. psychologist, neurologist, geriatrician) if we find } \\
\text { that a patient has cognitive impairment }\end{array}$ & 4.72 & 1.06 \\
\hline $\begin{array}{l}\text { 8. We use evidence-based care guidelines in the care of older cognitively impaired } \\
\text { patients }\end{array}$ & 4.14 & 1.28 \\
\hline $\begin{array}{l}\text { 9. We use biographical information about older patients' (e.g. habits, interests and wishes } \\
\text { etc.) to plan their care }\end{array}$ & 3.68 & 1.35 \\
\hline 10. We involve family members in the care of older patients with cognitive impairment & 4.79 & 0.95 \\
\hline $\begin{array}{l}\text { 11. We provide staff continuity for older patients with cognitive impairments (e.g. the } \\
\text { same nurses providing care to these patients as often as possible) }\end{array}$ & 3.31 & 1.44 \\
\hline $\begin{array}{l}\text { 12. We systematically evaluate whether or not older patients with cognitive impairment } \\
\text { receive care that meets their needs }\end{array}$ & 3.99 & 1.30 \\
\hline $\begin{array}{l}\text { 13. We involve older patients with cognitive impairment in decisions about their care (e.g. } \\
\text { examinations, treatments etc.) }\end{array}$ & 3.32 & 1.32 \\
\hline $\begin{array}{l}\text { 14. We ensure that older patients with cognitive impairment have tests/ consultations in } \\
\text { the unit rather than having to go to another department }\end{array}$ & 3.90 & 1.32 \\
\hline 15. We discuss ways to meet the complex care needs of people with cognitive impairment & 4.17 & 1.21 \\
\hline
\end{tabular}


Table 3 Mean and standard deviation of ADKS, DAS and POPAC scores and relationship between the three constructs and the POPAC sub-domains

\begin{tabular}{|c|c|c|c|c|c|c|}
\hline & $\mathbf{N}$ & Range & Minimum & Maximum & Mean & $\begin{array}{c}\text { Std. } \\
\text { Deviation }\end{array}$ \\
\hline ADKS & 128 & 19 & 11 & 30 & 20.37 & 3.720 \\
\hline DAS & 121 & 63 & 63 & 126 & 99.45 & 12.519 \\
\hline \multirow[t]{3}{*}{ POPAC } & 117 & 60 & 22 & 82 & 57.88 & 10.282 \\
\hline & \multicolumn{2}{|c|}{ ADKS } & \multicolumn{2}{|c|}{ DAS } & \multicolumn{2}{|c|}{ POPAC } \\
\hline & $\mathrm{R}^{\#}$ & $\mathrm{p}$-value & $\mathrm{R}^{\#}$ & p-value & $\mathrm{R}^{\#}$ & p-value \\
\hline ADKS & - & - & 0.105 & 0.250 & -0.205 & $0.026^{*}$ \\
\hline DAS & 0.105 & 0.250 & - & - & 0.311 & $0.001 * *$ \\
\hline $\begin{array}{c}\text { POPAC } \\
\text { (total) }\end{array}$ & -0.205 & $0.026^{*}$ & 0.311 & $0.001 * *$ & - & - \\
\hline $\begin{array}{c}\text { POPAC } \\
\text { (using } \\
\text { cognitive } \\
\text { assessments/ } \\
\text { care } \\
\text { interventions) } \\
\end{array}$ & -0.172 & 0.064 & 0.165 & 0.077 & - & - \\
\hline $\begin{array}{c}\text { POPAC } \\
\text { (using } \\
\text { evidence and } \\
\text { expertise in } \\
\text { cognition) } \\
\end{array}$ & -0.204 & $0.027 *$ & 0.197 & $0.034 *$ & - & - \\
\hline $\begin{array}{c}\text { POPAC } \\
\text { (individualizing } \\
\text { care) } \\
\end{array}$ & -0.214 & 0.182 & 0.336 & $<0.001 * *$ & - & - \\
\hline
\end{tabular}

\# Pearson or Spearman's Rho correlation coefficient

* Significant at the 0.05 level (2-tailed)

** Significant at the 0.01 level (2-tailed) 
Table 4. Univariate association between ADKS, DAS and POPAC scores and demographic variables

\begin{tabular}{|c|c|c|c|c|c|c|c|}
\hline Variables & & $\begin{array}{c}\text { Mean ADKS } \pm \text { SD } \\
(\mathbf{N})\end{array}$ & $\begin{array}{c}\text { p- } \\
\text { value }\end{array}$ & $\begin{array}{c}\text { Mean DAS } \pm \text { SD } \\
(\mathbf{N})\end{array}$ & p-value & $\begin{array}{c}\text { Mean } \\
\text { POPAC } \pm \text { SD }(\mathbf{N})\end{array}$ & p-value \\
\hline Gender & $\begin{array}{r}\text { Male } \\
\text { Female }\end{array}$ & $\begin{array}{l}20.06 \pm 4.24 \\
20.48 \pm 3.45\end{array}$ & 0.575 & $\begin{array}{l}94.72 \pm 14.96(32) \\
101.16 \pm 11.13(89)\end{array}$ & $0.012 *$ & $\begin{array}{l}58.10 \pm 12.56(32) \\
57.80 \pm 9.38(85)\end{array}$ & 0.891 \\
\hline Age & & & 0.735 & & $0.002 * *$ & & $0.003 * *$ \\
\hline Nationality & $\begin{array}{r}\text { Maltese } \\
\text { Other }\end{array}$ & $\begin{array}{l}20.77 \pm 3.52(104) \\
18.30 \pm 4.00(20)\end{array}$ & $0.006^{*}$ & $\begin{array}{l}99.85 \pm 12.65(100) \\
97.65 \pm 13.05(17)\end{array}$ & 0.510 & $\begin{array}{l}57.53 \pm 9.72(97) \\
59.12 \pm 12.63(17)\end{array}$ & 0.553 \\
\hline Occupation & $\begin{array}{r}\text { Careworker } \\
\text { Charge/deputy nurse } \\
\text { Medical Doctor } \\
\text { Nurse } \\
\text { Therapists } \\
\text { Social worker } \\
\text { Others } \\
\end{array}$ & $\begin{array}{l}19.09 \pm 5.32(11) \\
19.44 \pm 3.17(9) \\
22.60 \pm 5.41(5) \\
20.36 \pm 3.30(88) \\
21.71 \pm 1.10(7) \\
27.0 \pm 0.00(1) \\
19.72 \pm 5.03(7) \\
\end{array}$ & 0.062 & $\begin{array}{c}99.82 \pm 15.83(11) \\
96.14 \pm 9.03(7) \\
97.75 \pm 14.22(4) \\
100.70 \pm 12.14(85) \\
98.17 \pm 10.17(7) \\
99.00 \pm 0.00(1) \\
87.67 \pm 20.17(6) \\
\end{array}$ & 0.548 & $\begin{array}{c}63.25 \pm 13.01(8) \\
50.29 \pm 8.67(7) \\
54.40 \pm 7.02(5) \\
58.99 \pm 9.225(83) \\
58.43 \pm 6.18(7) \\
58.00 \pm 0.00(1) \\
46.50 \pm 19.50(6) \\
\end{array}$ & $0.007 *$ \\
\hline $\begin{array}{l}\text { Maximum level of } \\
\text { education } \\
\text { according to the } \\
\text { European } \\
\text { Qualification } \\
\text { Framework }\end{array}$ & $\begin{array}{l}\text { Level } 2 \\
\text { Level } 3 \\
\text { Level } 4 \\
\text { Level } 5 \\
\text { Level } 6 \\
\text { Level } 7\end{array}$ & $\begin{array}{c}19.31 \pm 5.67(13) \\
18.63 \pm 3.11(8) \\
19.89 \pm 3.79(9) \\
19.29 \pm 2.85(31) \\
21.58 \pm 3.6(26) \\
21.18 \pm 3.65(40)\end{array}$ & 0.068 & $\begin{array}{c}94.17 \pm 10.77(12) \\
101.25 \pm 18.58(8) \\
96.63 \pm 8.00(8) \\
103.28 \pm 12.38(29) \\
96.15 \pm 12.85(26) \\
100.84 \pm 11.82(37)\end{array}$ & & $\begin{array}{c}56.33 \pm 6.27(9) \\
61.63 \pm 14.3(8) \\
58.50 \pm 9.02(8) \\
59.87 \pm 10.55(30) \\
54.56 \pm 10.62(25) \\
58.06 \pm 9.95(36)\end{array}$ & 0.422 \\
\hline $\begin{array}{l}\text { Previous training } \\
\text { on dementia }\end{array}$ & $\begin{array}{r}\text { Yes } \\
\text { No }\end{array}$ & $\begin{array}{l}20.62 \pm 3.76(50) \\
20.21 \pm 3.75(76)\end{array}$ & 0.551 & $\begin{array}{c}101.33 \pm 10.76(48) \\
98.72 \pm 13.32(71)\end{array}$ & 0.260 & $\begin{array}{c}57.59 \pm 9.92(46) \\
58.14 \pm 10.64(69)\end{array}$ & 0.778 \\
\hline $\begin{array}{l}\text { Previous } \\
\text { experience in } \\
\text { geriatric/psychiatric } \\
\text { setting }\end{array}$ & $\begin{array}{l}\text { Yes } \\
\text { No }\end{array}$ & $\begin{array}{l}20.35 \pm 3.46(97) \\
20.79 \pm 4.35(29)\end{array}$ & 0.571 & $\begin{array}{c}100.68 \pm 12.02(94) \\
95.35 \pm 13.73(26)\end{array}$ & 0.055 & $\begin{array}{l}58.33 \pm 10.17(89) \\
56.48 \pm 10.91(27)\end{array}$ & 0.419 \\
\hline $\begin{array}{l}\text { Family member } \\
\text { with dementia }\end{array}$ & $\begin{array}{l}\text { Yes } \\
\text { No }\end{array}$ & $\begin{array}{l}21.91 \pm 3.35(33) \\
19.94 \pm 3.72(84)\end{array}$ & $0.009 *$ & $\begin{array}{c}98.26 \pm 10.38(31) \\
100.49 \pm 13.54(79)\end{array}$ & 0.410 & $\begin{array}{c}57.65 \pm 9.52(31) \\
57.59 \pm 10.92(75)\end{array}$ & 0.979 \\
\hline $\begin{array}{l}\text { Perceived } \\
\text { experience }^{\mathfrak{f}} \text { of } \\
\text { working with } \\
\text { dementia patients }\end{array}$ & $\begin{array}{r}\text { Very positive } \\
\text { Positive } \\
\text { Neutral } \\
\text { Negative } \\
\text { Very negative } \\
\end{array}$ & $\begin{array}{c}19.50 \pm 4.99(10) \\
20.63 \pm 2.77(30) \\
20.55 \pm 3.88(56) \\
20.88 \pm 3.18(16) \\
21.00 \pm 0.00(2) \\
\end{array}$ & 0.907 & $\begin{array}{c}102.11 \pm 5.97(9) \\
105.28 \pm 12.62(29) \\
98.02 \pm 12.43(52) \\
97.06 \pm 8.68(16) \\
80.00 \pm 1.41(2)\end{array}$ & $0.007^{*}$ & $\begin{array}{c}58.86 \pm 16.48(7) \\
59.31 \pm 9.48(29) \\
58.21 \pm 8.80(52) \\
56.60 \pm 11.53(15) \\
54.00 \pm 0.00(1)\end{array}$ & 0.919 \\
\hline
\end{tabular}

£Perceived experience: Range from very positive (1) to very negative (5)

* Significant at the 0.05 level (2-tailed)

** Significant at the 0.01 level (2-tailed)

SD: Standard Deviation 
Table 5 Stepwise multiple regression showing retained models of staff knowledge, attitudes and demographic variables as predictors of the perceived level of personcentred practices in the hospital wards

\begin{tabular}{|c|c|c|c|c|c|c|c|c|c|}
\hline Models & Predictor variables & B & SE* & 及 & $\mathbf{t}$ & p & $\Delta \mathbf{R}^{2}$ & $\begin{array}{l}\text { Adjusted } \\
\qquad \Delta \mathbf{R}^{\mathbf{2}}\end{array}$ & $\begin{array}{l}\text { F value; p- } \\
\text { value }\end{array}$ \\
\hline $\begin{array}{c}(\text { constant }) * \mathrm{DAS} \\
\text { score }\end{array}$ & $\begin{array}{r}\text { (constant) } \\
\text { DAS score }\end{array}$ & $\begin{array}{c}30.38 \\
0.27\end{array}$ & $\begin{array}{l}8.12 \\
0.08\end{array}$ & 0.33 & $\begin{array}{l}3.74 \\
3.42\end{array}$ & $\begin{array}{c}<0.001 \\
0.001\end{array}$ & 0.109 & 0.100 & $11.67 ; 0.001$ \\
\hline $\begin{array}{c}(\text { constant }) * \text { DAS } \\
\text { scores* ADKS score }\end{array}$ & $\begin{array}{r}\text { (constant) } \\
\text { DAS score } \\
\text { ADKS score }\end{array}$ & $\begin{array}{c}43.02 \\
0.28 \\
-0.66\end{array}$ & $\begin{array}{l}9.75 \\
0.08 \\
0.29\end{array}$ & $\begin{array}{c}0.34 \\
-0.21\end{array}$ & $\begin{array}{l}4.41 \\
3.62 \\
-2.24\end{array}$ & $\begin{array}{c}<0.001 \\
<0.001 \\
0.027\end{array}$ & 0.155 & 0.137 & $8.59 ;<0.001$ \\
\hline $\begin{array}{c}(\text { constant }) * \text { DAS } \\
\text { scores* ADKS score* } \\
\text { Age }\end{array}$ & $\begin{array}{r}\text { (constant) } \\
\text { DAS score } \\
\text { ADKS score } \\
\text { Age }\end{array}$ & $\begin{array}{c}54.02 \\
0.24 \\
-0.63 \\
-0.24\end{array}$ & $\begin{array}{c}10.98 \\
0.08 \\
0.29 \\
0.12\end{array}$ & $\begin{array}{l}0.29 \\
-0.20 \\
-0.20\end{array}$ & $\begin{array}{l}4.92 \\
3.00 \\
-2.18 \\
-2.05\end{array}$ & $\begin{array}{c}<0.000 \\
0.003 \\
0.032 \\
0.043\end{array}$ & 0.191 & 0.165 & $7.33 ;<0.001$ \\
\hline
\end{tabular}

Excluded variables in Model 1: Gender, Nationality, Age, Education, ADKS, Previous work, Previous training, Family member

Excluded variables in Model 2: Gender, Nationality, Age, Education, Previous work, Previous training, Family member

Excluded variables in Model 3: Gender, Nationality, Education, Previous work, Previous training, Family member 